\title{
Low-Cytotoxic Synthetic Bromorutaecarpine Exhibits Anti-Inflammation and Activation of Transient Receptor Potential Vanilloid Type 1 Activities
}

\author{
Chi-Ming Lee, ${ }^{1}$ Jiun-An Gu, ${ }^{2}$ Tin-Gan Rau, ${ }^{2}$ Che-Hsiung Yang, ${ }^{1}$ Wei-Chi Yang, \\ Shih-Hao Huang, ${ }^{3}$ Feng-Yen Lin, ${ }^{4}$ Chun-Mao Lin, ${ }^{5,6}$ and Sheng-Tung Huang ${ }^{7}$ \\ ${ }^{1}$ Graduate Institute of Medical Sciences, College of Medicine, Taipei Medical University, No. 250, Wu-xing Street, Taipei 110, Taiwan \\ ${ }^{2}$ Institute of Chemical Engineering, College of Engineering, National Taipei University of Technology, Taipei, Taiwan \\ ${ }^{3}$ Department of Food and Beverage Management, Taipei College of Maritime Technology, Taipei, Taiwan \\ ${ }^{4}$ Department of Internal Medicine, School of Medicine, Taipei Medical University, No. 250, Wu-xing Street, Taipei 110, Taiwan \\ ${ }^{5}$ Department of Biochemistry, College of Medicine, Taipei Medical University, No. 250, Wu-xing Street, Taipei 110, Taiwan \\ ${ }^{6}$ Orthopedics Research Center, Taipei Medical University Hospital, Taipei, Taiwan \\ ${ }^{7}$ Institute of Biochemical and Biomedical Engineering, College of Engineering, National Taipei University of Technology, Taipei, Taiwan
}

Correspondence should be addressed to Chun-Mao Lin; cmlin@tmu.edu.tw and Sheng-Tung Huang; ws75624@ntut.edu.tw

Received 12 September 2013; Accepted 29 October 2013

Academic Editor: Joen-Rong Sheu

Copyright (C) 2013 Chi-Ming Lee et al. This is an open access article distributed under the Creative Commons Attribution License, which permits unrestricted use, distribution, and reproduction in any medium, provided the original work is properly cited.

Rutaecarpine (RUT), the major bioactive ingredient isolated from the Chinese herb Evodia rutaecarpa, possesses a wide spectrum of biological activities, including anti-inflammation and preventing cardiovascular diseases. However, its high cytotoxicity hampers pharmaceutical development. We designed and synthesized a derivative of RUT, bromo-dimethoxyrutaecarpine (Br-RUT), which showed no cytotoxicity at $20 \mu \mathrm{M}$. Br-RUT suppressed nitric oxide (NO) production and tumor necrosis factor- $\alpha$ release in concentration-dependent $(0 \sim 20 \mu \mathrm{M})$ manners in lipopolysaccharide (LPS)-treated RAW 264.7 macrophages; protein levels of inducible NO synthase (iNOS) and cyclooxygenase- 2 induced by LPS were downregulated. Br-RUT inhibited cell migration and invasion of ovarian carcinoma A2780 cells with $0 \sim 48$ h of treatment. Furthermore, Br-RUT enhanced the expression of transient receptor potential vanilloid type 1 and activated endothelial NOS in human aortic endothelial cells. These results suggest that the synthetic Br-RUT possesses very low cytotoxicity but retains its activities against inflammation and vasodilation that could be beneficial for cardiovascular disease therapeutics.

\section{Introduction}

Evodiamine (EVO) and rutaecarpine (RUT), major bioactive ingredients isolated from the Chinese herb Evodia rutaecarpa [1], possess a wide spectrum of biological activities [2]. Inflammation and low oxygen diffusion are characteristics of atherosclerosis. EVO repressed cyclooxygenase (COX)-2 and inducible nitric oxide (NO) synthase (iNOS) expression mediated via inhibition of hypoxia-inducible factor (HIF)- $1 \alpha$ under hypoxic conditions [3]. Therefore, EVO is considered an effective therapeutic agent against inflammatory diseases involving hypoxia. Vasorelaxant effects of EVO and RUT in rat isolated mesenteric arteries were reported to be associated with $\mathrm{Ca}^{2+}$ flux activity $[4,5]$. RUT lowered blood pressure through the endothelial $\mathrm{Ca}^{2+}-\mathrm{NO}-\mathrm{cGMP}$ pathway to reduce smooth muscle tone [6].

The calcitonin gene-related peptide (CGRP), a major neurotransmitter of capsaicin-sensitive sensory nerves, plays a key role in maintaining endothelial homoeostasis. Decreased plasma CGRP levels caused cardiac susceptibility to ischemia-reperfusion injury, and antihypertensive therapy with RUT reversed cardiac susceptibility to reperfusion injury by stimulating CGRP release $[7,8]$. The CGRP can counteract angiotensin (Ang) II-induced endothelial progenitor cell senescence through downregulating NADPH oxidase and reactive oxygen species (ROS) production [9]. 
Stimulation of endogenous CGRP release via activation of vanilloid receptors plays an important role in the vasodilatory effects of RUT [10, 11]. Activation of transient receptor potential vanilloid type 1 (TRPV1), a ligand-gated cationic channel, by EVO in endothelial cells may protect against certain cardiovascular diseases (CVDs) such as hypertension and stroke $[12,13]$. Okada et al. reported that TRPV1 is a potential drug target for improving the outcome of inflammatory fibrosis [14]. NO release with consequent activation of endothelial (e)NOS confers vascular relaxation mediated by CGRP and TRPV1 stimulation [15]. The effect of EVO in TRPV1-dependent atheroprotection was further confirmed in mice [16]. Sheu et al. reported that RUT is a potential therapeutic agent for arterial thromboses because of its in vivo antiplatelet effect $[17,18]$. Alkaloid compounds also exhibit anticancer activities both in vitro and in vivo by inducing cell-cycle arrest or apoptosis [19].

RUT and EVO showed quite high toxicity to porcine brain capillary endothelial cells (ECs) [20], which limits their application in vascular diseases. A variety of structural modifications of natural products were designed and synthesized for superior biological applications. Structure-activity relationship studies were further performed and are in progress [21-23]. RUT analogues were designed and synthesized to activate TRPV1 for enhanced vasodilator and hypotensive effects. The 14-N atom of RUT is critical for its activity [24]. Synthetic derivatives of RUT in this study exhibited very low cytotoxicity, but they still maintained their anti-inflammatory activity and TRPV1-upregulating effects. Results provide insights into the use of this TRPV1 agonist from RUT in vascular disease therapeutics.

\section{Materials and Methods}

2.1. Chemicals and General Methods. All chemicals were purchased from Acros Organics (Geel, Belgium), Sigma-Aldrich (St. Louis, MO), Showa Chemical Industry (Tokyo, Japan), or TCI America (Portland, OR) and were used without further purification. All reactions requiring anhydrous conditions were performed in oven-dried glassware under an $\mathrm{Ar}$ or $\mathrm{N}_{2}$ atmosphere. Chemicals and solvents were either used without purification or purified by standard techniques. Analytical thin-layer chromatography (TLC) was performed on glass plate-mounted silica gel 60F254 (Merck) at a thickness of $0.2 \mathrm{~mm}$. Flash column chromatography was performed using Silicycle silica gel 60. Synthesized compounds were characterized using $1 \mathrm{H}$ nuclear magnetic resonance (NMR) (Bruker Avance $500 \mathrm{MHz}$, Billerica, MA) and Fourier-transformed infrared spectroscopy (FT-IR).

2.2. Synthesis of Bromo-(Br-)RUT Derivatives. 2-Amino-4,5dimethoxybenzoic acid (6 of Scheme 1) (0.4 g, $2 \mathrm{mmol}$ ) was dissolved in toluene $(6 \mathrm{~mL})$ that had been cooled to $0^{\circ} \mathrm{C}$. Thionyl chloride $(0.75 \mathrm{~mL}, 10 \mathrm{mmol})$ was added dropwise to the ice-cold solution. The reaction mixture was heated to $70 \sim 80^{\circ} \mathrm{C}$ and stirred for $1 \mathrm{~h}$. The solution was heated to reflux for $10 \mathrm{~min}$, was allowed to cool to $23^{\circ} \mathrm{C}$, and was concentrated under reduced pressure. The resulting residue was redissolved in toluene $(6 \mathrm{~mL})$. A compound of 2,3-piperidinedione-3-(4bromophenyl) hydrazone ( 5 of Scheme 1$)$ ( $0.35 \mathrm{~g}, 1.37 \mathrm{mmol}$ ) was added to the solution. The reaction mixture was heated to reflux and stirred overnight. The solution was concentrated on a rotary evaporator, $10 \%$ sodium carbonate aqueous was added $(200 \mathrm{~mL})$, and the reaction was extracted with dichloromethane $(3 \times 200 \mathrm{~mL})$. The organic layer was dried over anhydrous $\mathrm{MgSO}_{4}$, the solids were filtered through a fritted Büchner funnel, and the solution was concentrated under reduced pressure. The residue was purified by column chromatography (elution with DCM:methanol of $40: 1$ ), affording Br-RUT as a solid.

2.3. Cell Culture. The RAW 264.7 macrophage cell line and A2780 ovarian carcinoma cells were grown in Dulbecco's modified Eagle's medium (DMEM) containing 10\% fetal bovine serum (FBS), $100 \mathrm{U} / \mathrm{mL}$ penicillin, $100 \mu \mathrm{g} / \mathrm{mL}$ streptomycin, $4 \mathrm{mM}$ L-glutamine, $4.5 \mathrm{~g} / \mathrm{L}$ glucose, $1 \mathrm{mM}$ sodium pyruvate, and $1.5 \mathrm{~g} / \mathrm{L}$ sodium bicarbonate at $37^{\circ} \mathrm{C}$ in a humidified atmosphere with $5 \% \mathrm{CO}_{2}$. Primary human aortic ECs (HAECs) and human coronary artery ECs (HCAECs) were grown in a MesoEndo Endothelial Cell Growth Medium Kit (Cell Applications, San Diego, CA) supplemented with 10\% $\mathrm{FBS}$ at $37^{\circ} \mathrm{C}$ in a humidified atmosphere with $5 \% \mathrm{CO}_{2}$.

2.4. Nitrite Assay. NO production in cell culture supernatant was evaluated by measuring the nitrite concentration. The nitrite concentration was detected with the Griess reaction. RAW 264.7 macrophages were plated at a density of $2 \times 10^{5}$ cells $/ \mathrm{mL}$ in 24 -well plates for $24 \mathrm{~h}$, followed by cotreatment with different concentrations of Br-RUT and lipopolysaccharide (LPS) $(100 \mathrm{ng} / \mathrm{mL})$ for $24 \mathrm{~h}$. The amount of nitrite in the samples was detected using the Griess reagent ( $1 \%$ sulfanilamide in $5 \%$ phosphoric acid and $0.1 \%$ naphthyl ethylenediamine dihydrochloride dihydrochloride in water). Data are reported as the mean \pm standard error of the mean (SEM) of three independent determinations [25].

2.5. TNF- $\alpha$ Assay. Soluble cytokines were tested in supernatants of cultured RAW 264.7 macrophages by an enzyme-linked immunosorbent assay (ELISA). RAW 264.7 macrophages were plated at a density of $10^{4}$ cells $/ \mathrm{mL}$ in 96-well plates for $12 \mathrm{~h}$, followed by treatment with different concentrations of Br-RUT for $1 \mathrm{~h}$, then treatment with LPS $(100 \mathrm{ng} / \mathrm{mL})$ for $12 \mathrm{~h}$. TNF- $\alpha$ in cell supernatants was detected using a mouse TNF- $\alpha$ Quantikine kit (R\&D Systems, Minneapolis, MN) which was carried out according to the manufacturer's instructions. The absorbance was read at $450 \mathrm{~nm}$ with an ELISA plate reader. Data are reported as the mean \pm SEM of three independent determinations.

2.6. Western Blot Analysis. Protein samples were resolved by sodium dodecylsulfate polyacrylamide gel electrophoresis (SDS-PAGE) and electrotransferred onto a polyvinylidene difluoride membrane. The membrane was incubated with a primary antibody at $4^{\circ} \mathrm{C}$ overnight and then incubated with a horseradish peroxidase (HRP)-conjugated secondary immunoglobulin $\mathrm{G}$ antibody; immunoreactive bands were 


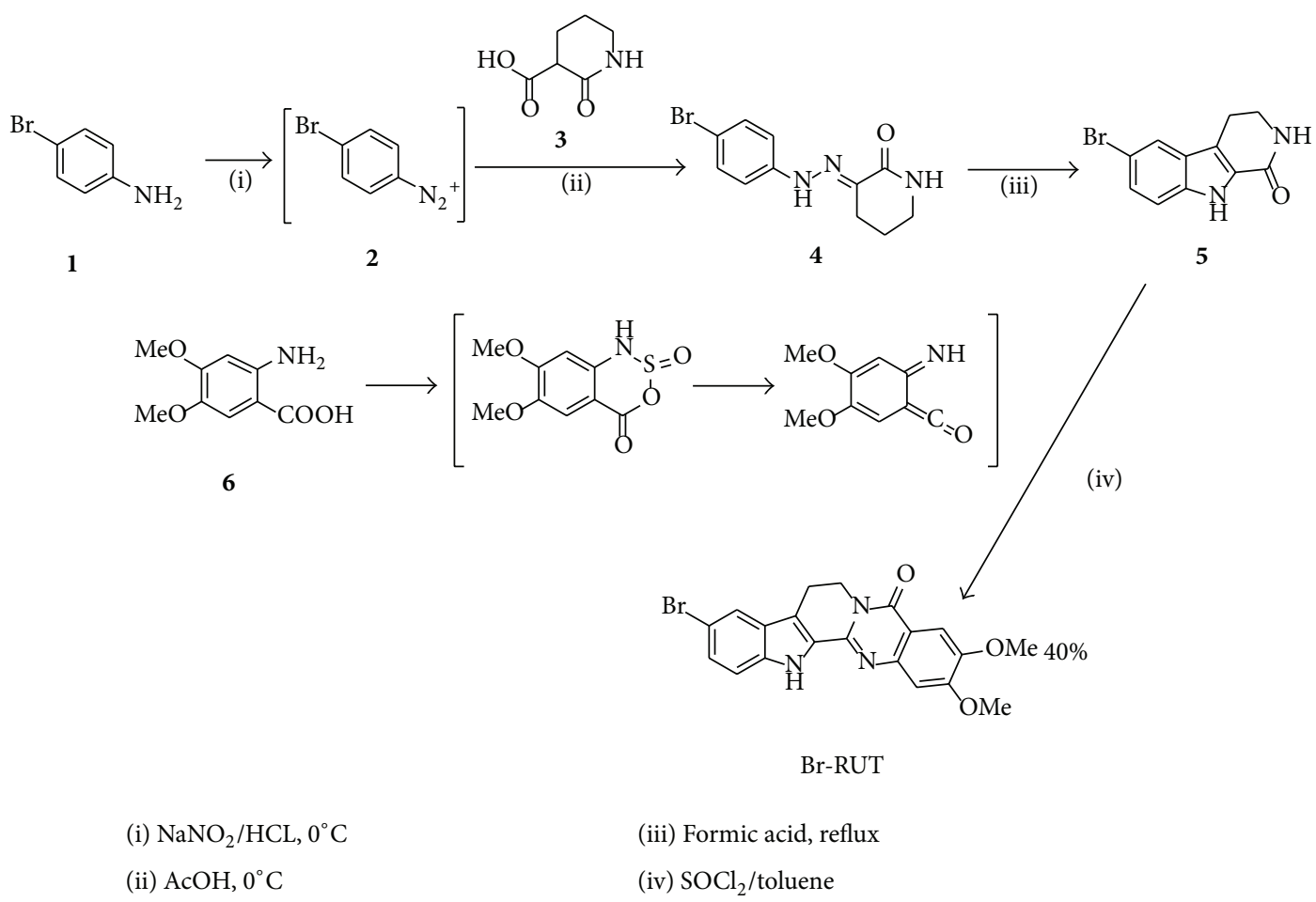

SCHEME 1: Synthesis of bromo-dimethoxyrutaecarpine (Br-RUT).

visualized with PerkinElmer enhanced chemiluminescent reagents [26].

2.7. Cell Viability Assay. An MTT assay to test the cytotoxicity of reagents and cell viability was performed as described previously, based on conversion of the yellow tetrazolium salt to the purple formazan product [27]. Cells $\left(10^{4}\right.$ cells/well) were grown on a 96-well plate supplemented with culture medium. Cells were treated with Br-RUT $(0 \sim 20 \mu \mathrm{M})$ for $24 \mathrm{~h}$, and an MTT stock solution (5 mg of MTT/mL of phosphatebuffered saline; PBS) was added to the growing cultures for $2 \mathrm{~h}$. The absorbance was measured with a spectrophotometer at $560 \mathrm{~nm}$. A blank with DMSO alone was measured as a reading control.

2.8. Wound Healing Migration Assay. A2780 cells at a density of $2 \times 10^{5}$ cells/well in 6 -well plates were incubated at $37^{\circ} \mathrm{C}$ for $24 \mathrm{~h}$. Cells were scratched with a $200-\mu \mathrm{L}$ pipette tip, and cells in the plate were washed with PBS, and then new complete medium was added and treated with or without 1 and $2.5 \mu \mathrm{M}$ of cantharidin for $24 \mathrm{~h}$; $0.5 \%$ DMSO served as a vehicle control. At the end of incubation, cells were examined and photographed under a fluorescence microscope. The number of cells that had migrated into the scratched area was calculated as described elsewhere [28].

2.9. In Vitro Invasion Assay. A2780 cell migration or invasion was evaluated using 24 -well Transwell inserts ( $8 \mu \mathrm{m}$ pore filters, Merck Millipore) individually coated with Matrigel (BD Biosciences, Bedford, MA). A2780 cells $\left(2 \times 10^{4}\right.$ cells/well $)$ were cultured for $24 \mathrm{~h}$ in serum-free DMEM, and then cells were placed in the upper chamber of the Transwell insert and treated with $0.5 \%$ DMSO (as a control) or Br-RUT $(1.25$ or $2.5 \mu \mathrm{M})$ for $24 \mathrm{~h}$. Medium containing $10 \%$ FBS was placed in the lower chamber. At the end of incubation, nonmigrated cells were removed using a cotton swab; invaded cells maintained in the upper chamber were fixed with $4 \%$ formaldehyde and stained with $2 \%$ crystal violet. On the lower surface of the filter, cells that had penetrated were counted and photographed under a phase-contract microscope at 200x magnification. Three independent experiments were performed as described elsewhere [28].

\section{Results}

3.1. Design and Synthesis of Br-RUT. The synthetic schemes for preparing Br-RUT derivatives are outlined in Scheme 1. The main intermediate, substituted carboline (5), was prepared from substituted aniline following a procedure described by Henecka et al. [29] and Narayanan et al. [30]. The aniline (1) underwent the Sandmeyer reaction to give a diazonium salt, which was then coupled to carboxylic acid (3) to yield hydrazone (4), and treatment of hydrazone (4) in an acidic condition gave carboline (5) in a $56 \%$ yield ( 3 steps). Carboline (5) (see Figure S1 in Supplementary Material available online at http://dx/doi.org/10.1155/2013/795095) was then coupled with an in situ activated substituted oaminobenzoic acid derivative (6), which was pretreated with thionyl chloride in the presence of toluene at $70 \sim 80^{\circ} \mathrm{C}$ to provide Br-RUT in a $40 \%$ overall yield (4 steps). The chemical structures of the synthetic intermediates and final products were determined by ${ }^{1} \mathrm{H}$ and ${ }^{13} \mathrm{C}$ NMR, IR, and 


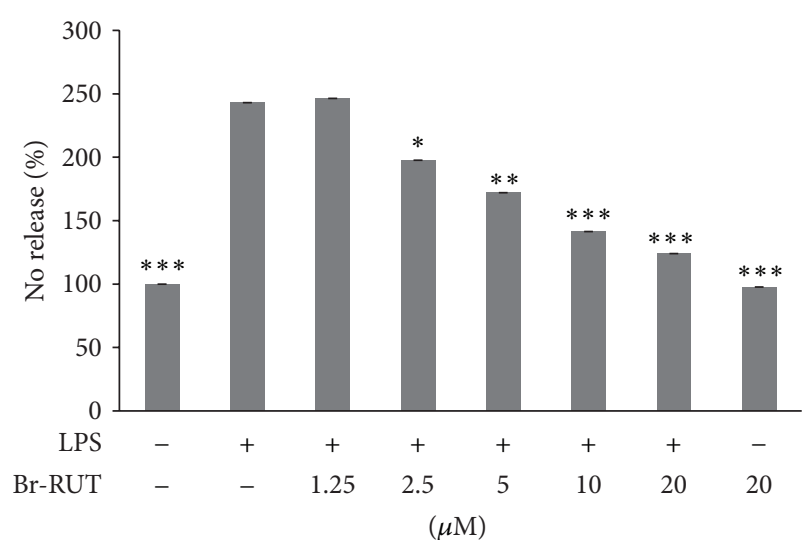

(a)

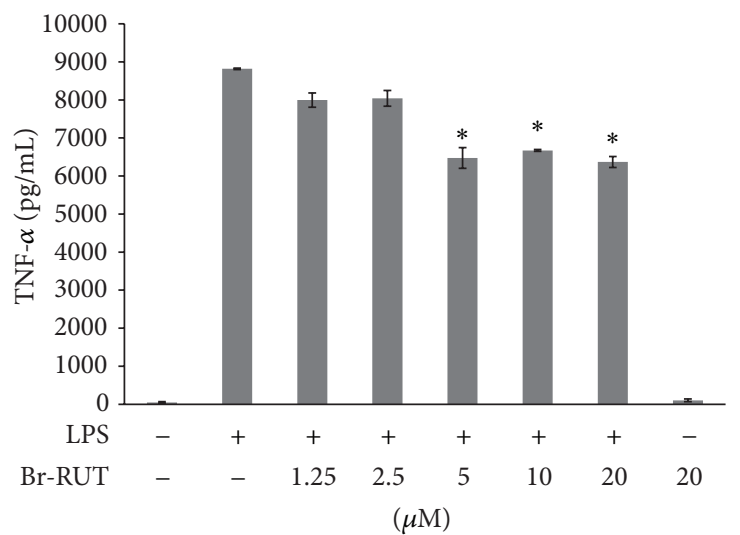

(b)

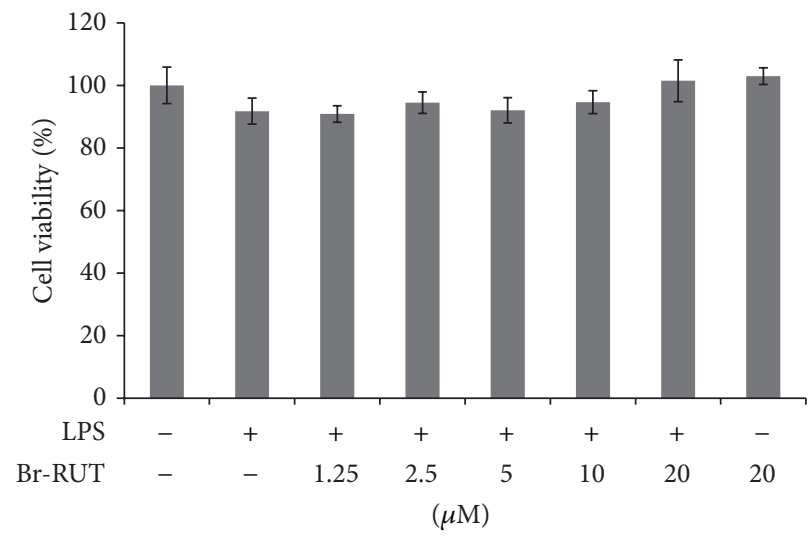

(c)

FigURE 1: Effects of bromo-dimethoxyrutaecarpine (Br-RUT) on nitric oxide (NO) and tumor necrosis factor (TNF)- $\alpha$ releases by lipopolysaccharide (LPS)-treated (100 ng/mL) RAW 264.7 macrophages. (a) NO levels were detected in culture medium using the Griess reaction. The percentage of untreated cells was set as the control to $100 \%$. (b) TNF- $\alpha$ release in cell supernatants was detected using a mouse TNF- $\alpha$ Quantikine kit. (c) Cell viability upon Br-BUT treatment for $24 \mathrm{~h}$ in an MTT assay. Statistical significance is indicated compared to LPS treatment. $\left({ }^{*} P<0.05,{ }^{* *} P<0.001,{ }^{* * *} P<0.001\right)$.

mass spectrometry. FT-IR (KBr, cm-1): $3330(\mathrm{~N}-\mathrm{H})$ and 1668 (carbonyl group) (Supplementary Figure S2). 1H-NMR (DDMSO, ppm) (Supplementary Figure S2): $\delta 3.13(t, J=6.8 \mathrm{~Hz}$, $2 \mathrm{H}), 3.87(\mathrm{~s}, 3 \mathrm{H}), 3.91(\mathrm{~s}, 3 \mathrm{H}), 4.41(t, J=6.8 \mathrm{~Hz}, 2 \mathrm{H}), 7.05$ (s, $1 \mathrm{H}), 7.34(d d, J=8.61 .4,1 \mathrm{H}), 7.41(d, J=8.6,1 \mathrm{H}), 7.47(s, 1 \mathrm{H})$, $7.85(s, 1 \mathrm{H}), 11.97(s, 1 \mathrm{H})$ (Supplementary Figure S3). MS-EI $(\mathrm{m} / \mathrm{z})$ : calcd. 426.2; found 425.6 (Supplementary Figure S4).

3.2. NO and TNF- $\alpha$ Release by LPS-Treated Macrophages was Suppressed by Br-RUT. NO production by LPS-treated RAW264.7 macrophages increased compared to untreated cells. Pretreatment for $1 \mathrm{~h}$ with synthetic Br-RUT suppressed NO production in a concentration-dependent $(0 \sim 20 \mu \mathrm{M})$ manner $(P<0.01)$ (Figure $1(\mathrm{a}))$. TNF- $\alpha$ released into the medium also showed consistent potency in a concentrationdependent $(0 \sim 20 \mu \mathrm{M})$ (Figure 1(b)) suppressive effect. Suppressive effects were not due to the reduction of cell number because Br-RUT showed no cytotoxicity at concentrations of 0 20 $\mu \mathrm{M}$ (Figure 1(c)).

3.3. Br-RUT Suppressed iNOS and COX-2 Protein Expressions by LPS-Treated Macrophages. We investigated the effects of
Br-RUT on protein levels of iNOS and COX-2. LPS-treated RAW 264.7 macrophages exhibited significantly elevated protein amounts of iNOS and COX-2, while Br-RUT suppressed their expressions in concentration-dependent manners (Figure 2). GAPDH protein levels of the loading controls remained constant.

3.4. Br-RUT Inhibited Cell Migration/Invasion. The effects of Br-RUT on inhibiting cell migration and invasion were investigated. As illustrated in Figure 3(a), wound healing assays used an ovarian carcinoma A2780 cell line in the presence of Br-RUT $(0 \sim 5 \mu \mathrm{M})$ for $0 \sim 48 \mathrm{~h}$. The migration velocity was measured using imaging software, and Student's $t$-test was used for the statistical analysis. Br-RUT showed significant effects against cell migration. Br-RUT $(0 \sim 2.5 \mu \mathrm{M})$ treatments for $24 \mathrm{~h}$ also exhibited invasion-inhibitory activity in a transwell assay (Figure 3(b)).

3.5. Br-RUT Activated TRPV1 and eNOS. TRPV1 is reportedly present in ECs of arteries. To validate the expression of TRPV1 in the endothelium, the TRPV1 protein of HAECs was 


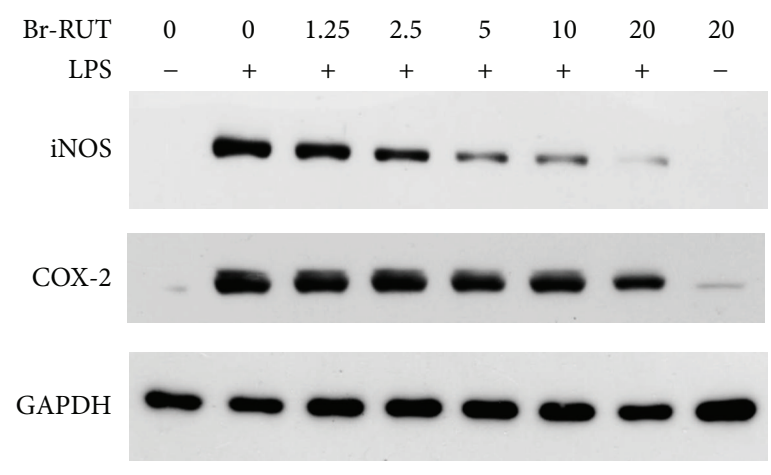

FIGURE 2

$24 \mathrm{hr}$
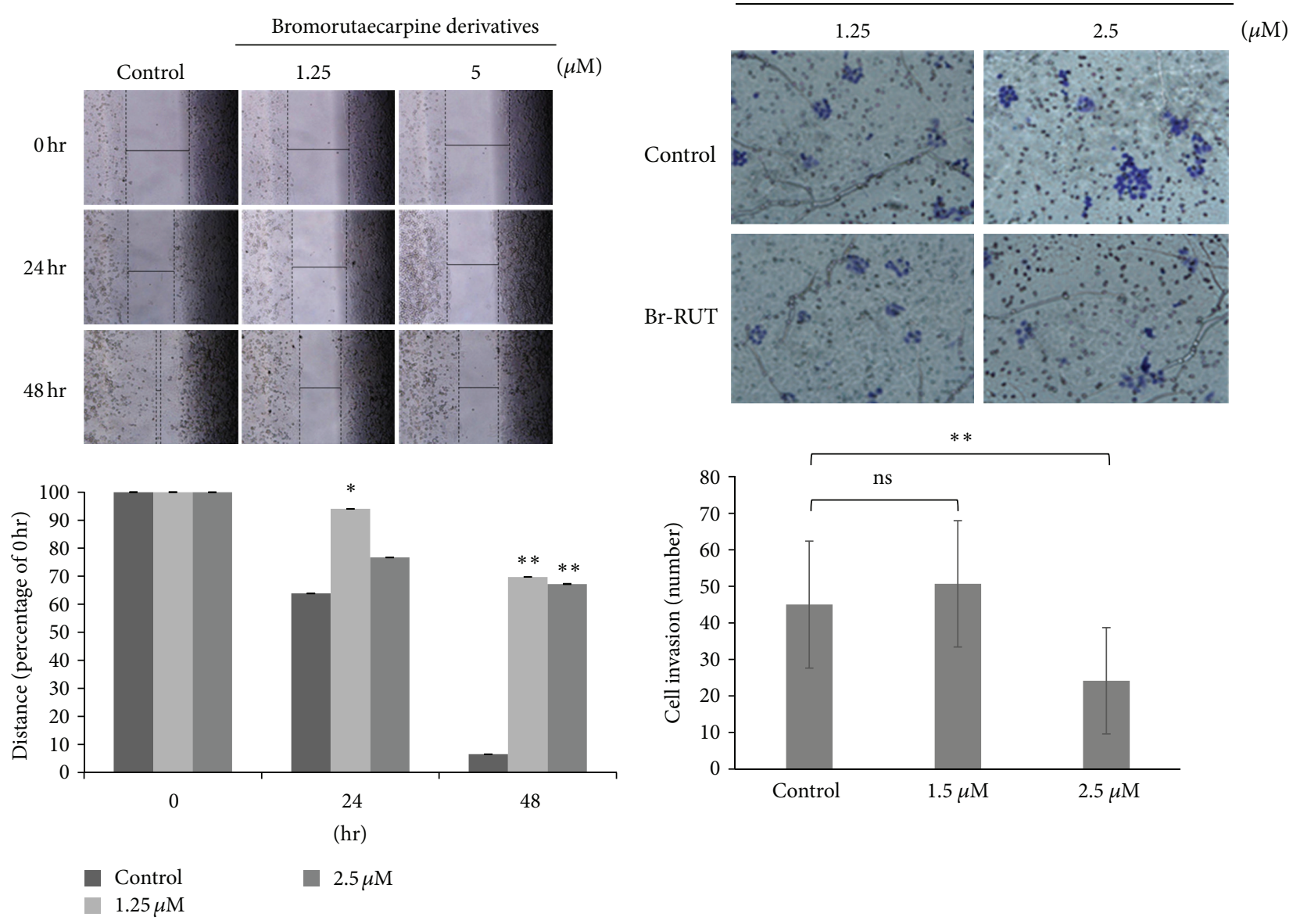

(a)

(b)

FIGURE 3: Effects of bromo-dimethoxyrutaecarpine (Br-RUT) on cell migration and invasion. Cell migration (a) and invasion (b) were detected following Br-RUT treatment for $0 \sim 48 \mathrm{~h}$ and photographed with a microscope (upper panel). Stained cells were counted and calculated in three random regions for each sample, results are presented as the mean \pm SD from triplicate experiments, and the statistical analysis is shown in the lower panel.

detected by immunoblotting. Br-RUT treatment $(10 \mu \mathrm{M})$ for $24 \mathrm{~h}$ increased TRPV1 protein amounts by 3.6 -fold compared to the control group after normalization with $\alpha$-tubulin levels (Figure 4). We further examined the effect of Br-RUT on the phosphorylation of NOS in HAECs because NO production is mainly regulated by eNOS phosphorylation. Br-RUT treatment $(10 \mu \mathrm{M})$ for $24 \mathrm{~h}$ significantly increased eNOS phosphorylation by 5.5 -fold compared to the control group after normalization with unphosphorylated eNOS (lower panel). Similar results were found in HCAECs (Supplementary Figure S5). Br-RUT upregulated the expression of TRPV1 and activated eNOS of ECs. 


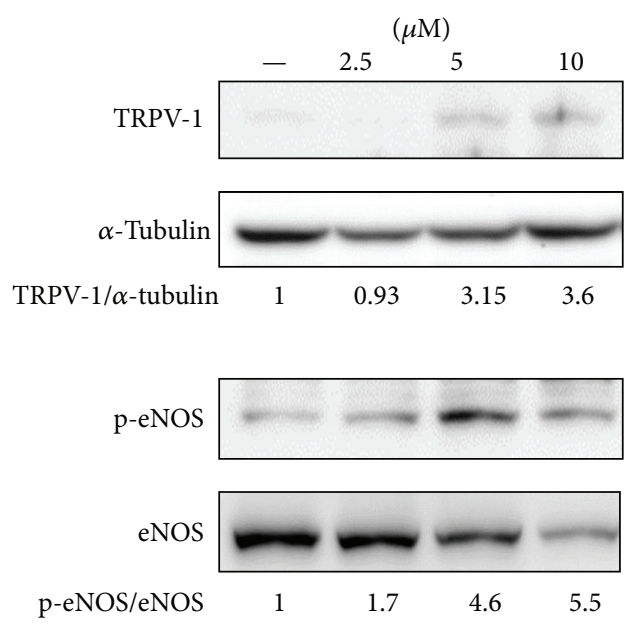

FIGURE 4: Effects of bromo-dimethoxyrutaecarpine (Br-RUT) on transient receptor potential vanilloid type 1 (TRPV1) expression and endothelial nitric oxide synthase (eNOS) phosphorylation in human aortic endothelial cells (HAECs). The densitometric ratio is indicated.

\section{Discussion}

The anti-inflammatory activities of EVO and RUT were reported $[4,31]$, but they act through different mechanisms, because EVO inhibits COX-2 induction and nuclear factor (NF) $-\kappa$ B activation in LPS-treated RAW 264.7 cells, while RUT does not [32]. RUT was reported to cause vasodilator effects by stimulating CGRP synthesis and release via activation of TRPV1. Its analogues were designed and synthesized for better vasodilator effects. Structural modifications of RUT and EVO were designed to enhance their biological activities. However, increased cytotoxicity hampers their application to vascular disorders [20,33]. Br-RUT, a novel analogue synthesized in this study, had very low cytotoxicity and showed antiinflammatory and migration/invasion-suppression activities that were beneficial with reduced side effects, so it has the potential to be developed for pharmaceutical applications.

RUT exerts different mechanisms to modulate signaling pathways, which resulted in different cell fates with diverse cell types and growth conditions [34]. RUT relaxed vascular smooth muscles by stimulating CGRP release via activation of vanilloid receptor subtype 1 [35]. It also antagonized Ang II-induced decreases in cellular NO contents and eNOS activities in rat vascular smooth muscle cells [36]. Compared to RUT, Br-RUT showed much less cytotoxicity, but it retained the anti-inflammatory activity. Br-RUT suppressed iNOS in macrophages, while it activated eNOS in ECs. Results showed that Br-Rut, derived from RUT, has enhanced beneficial effects and reduced adverse activities. Br-RUT, a modified derivative of RUT, retains the activities of improving cardiac and vasodilation functions but has fewer side effects.

Cells of the heart arise through a series of epithelialto-mesenchymal transitions (EMTs), followed by formation of new epithelial structures by the reverse process of a mesenchymal-to-epithelial transition (MET) and then differentiation into cardiomyocyte and endocardial lineages.
ECs from the atrioventricular canal undergo a tertiary EMT, called EndMT (due to the original properties of the tissue), and cells later assemble into the atrioventricular valvuloseptal complex [37]. Recent studies revealed that many cardiac diseases caused by inflammation are associated with fibrosis in the heart. Fibrosis is characterized by the accumulation of fibroblasts and the production of extracellular matrix. EndMT plays important roles in cardiac fibroblast formation during pathological progression. EndMT is regulated by signaling pathways mediated by inflammation-associated cytokines [38]. The endothelium is a promising target for drug treatment because it is in direct contact with the bloodstream. Br-RUT possesses anti-inflammatory activity and suppresses migration/invasion activities, phenomena that are associated with EndMT-associated fibrosis. Activation of TRPV1 and eNOS by Br-RUT suggests its potential for preventing vasorelaxation/hypertension. We therefore propose that inhibition of mechanisms for the formation of cardiac fibroblasts via EndMT by Br-RUT may provide a new strategy for heart disease therapeutics.

\section{Conclusions}

Br-RUT, a modified derivative of RUT, possesses very low cytotoxicity but retains its activity against inflammation. Treatment with Br-RUT enhanced TRPV1 and eNOS activities that may be beneficial by improving cardiac and vasodilation function.

\section{Conflict of Interests}

The authors declare that no conflict of interests exists.

\section{Authors' Contribution}

Chun-Mao Lin and Sheng-Tung Huang contributed equally to the work.

\section{Acknowledgments}

This study was supported by the National Taipei University of Technology and Taipei Medical University Join Research Grant (NTUT-TMU-102-12).

\section{References}

[1] J. J. Lu, J. L. Bao, X. P. Chen, M. Huang, and Y. T. Wang, "Alkaloids isolated from natural herbs as the anticancer agents," Evidence-Based Complementary and Alternative Medicine, vol. 2012, Article ID 485042, 12 pages, 2012.

[2] H. Yu, H. Jin, W. Gong, Z. Wang, and H. Liang, "Pharmacological actions of multi-target-directed evodiamine," Molecules, vol. 18, no. 2, pp. 1826-1843, 2013.

[3] Y.-N. Liu, S.-L. Pan, C.-H. Liao et al., "Evodiamine represses hypoxia-induced inflammatory proteins expression and hypoxia-inducible factor $1 \alpha$ accumulation in RAW264.7," Shock, vol. 32, no. 3, pp. 263-269, 2009.

[4] W.-F. Chiou, C.-J. Chou, A. Y.-C. Shum, and C.-F. Chen, "The vasorelaxant effect of evodiamine in rat isolated mesenteric 
arteries: mode of action," European Journal of Pharmacology, vol. 215, no. 2-3, pp. 277-283, 1992.

[5] W.-F. Chiou, A. Y.-C. Shum, J.-F. Liao, and C.-F. Chen, "Studies of the cellular mechanisms underlying the vasorelaxant effects of rutaecarpine, a bioactive component extracted from an herbal drug," Journal of Cardiovascular Pharmacology, vol. 29, no. 4, pp. 490-498, 1997.

[6] G.-J. Wang, X.-C. Wu, C.-F. Chen et al., "Vasorelaxing action of rutaecarpine: effects of rutaecarpine on calcium channel activities in vascular endothelial and smooth muscle cells," Journal of Pharmacology and Experimental Therapeutics, vol. 289, no. 3, pp. 1237-1244, 1999.

[7] D. Li, X.-J. Zhang, L. Chen et al., "Calcitonin gene-related peptide mediates the cardioprotective effects of rutaecarpine against ischaemia-reperfusion injury in spontaneously hypertensive rats," Clinical and Experimental Pharmacology and Physiology, vol. 36, no. 7, pp. 662-667, 2009.

[8] D. Li, J. Peng, H.-Y. Xin et al., "Calcitonin gene-related peptidemediated antihypertensive and anti-platelet effects by rutaecarpine in spontaneously hypertensive rats," Peptides, vol. 29, no. 10, pp. 1781-1788, 2008.

[9] Z. Zhou, C.-P. Hu, C.-J. Wang, T.-T. Li, J. Peng, and Y.-J. Li, “Calcitonin gene-related peptide inhibits angiotensin II-induced endothelial progenitor cells senescence through up-regulation of klotho expression," Atherosclerosis, vol. 213, no. 1, pp. 92101, 2010.

[10] C.-P. Hu, L. Xiao, H.-W. Deng, and Y.-J. Li, “The depressor and vasodilator effects of rutaecarpine are mediated by calcitonin gene-related peptide," Planta Medica, vol. 69, no. 2, pp. 125-129, 2003.

[11] P.-Y. Deng, F. Ye, W.-J. Cai et al., "Stimulation of calcitonin generelated peptide synthesis and release: mechanisms for a novel antihypertensive drug, rutaecarpine," Journal of Hypertension, vol. 22, no. 9, pp. 1819-1829, 2004.

[12] L. C. Ching, C. Y. Chen, K. H. Su et al., "Implication of AMPactivated protein kinase in transient receptor potential vanilloid type 1-mediated activation of endothelial nitric oxide synthase," Molecular Medicine, vol. 18, pp. 805-815, 2012.

[13] L.-C. Ching, Y. R. Kou, S.-K. Shyue et al., "Molecular mechanisms of activation of endothelial nitric oxide synthase mediated by transient receptor potential vanilloid type 1," Cardiovascular Research, vol. 91, no. 3, pp. 492-501, 2011.

[14] Y. Okada, P. S. Reinach, K. Shirai et al., "TRPV1 involvement in inflammatory tissue fibrosis in mice," American Journal of Pathology, vol. 178, no. 6, pp. 2654-2664, 2011.

[15] J. C. Torres-Narvaez, V. M. Ldel, E. V. Lopez et al., "Role of the transient receptor potential vanilloid type 1 receptor and stretch-activated ion channels in nitric oxide release from endothelial cells of the aorta and heart in rats," Experimental and Clinical Cardiology, vol. 17, no. 3, pp. 89-94, 2012.

[16] J. Wei, L. C. Ching, J. F. Zhao et al., "Essential role of transient receptor potential vanilloid type 1 in evodiamine-mediated protection against atherosclerosis," Acta Physiologica, vol. 207, no. 2, pp. 299-307, 2013.

[17] J. R. Sheu, W. C. Hung, C. H. Wu, Y. M. Lee, and M. H. Yen, "Antithrombotic effect of rutaecarpine, an alkaloid isolated from Evodia rutaecarpa, on platelet plug formation in in vivo experiments," British Journal of Haematology, vol. 110, no. 1, pp. 110-115, 2000.

[18] J.-R. Sheu, Y.-C. Kan, W.-C. Hung et al., "The antiplatelet activity of rutaecarpine, an alkaloid isolated from Evodia rutaecarpa, is mediated through inhibition of phospholipase C," Thrombosis Research, vol. 92, no. 2, pp. 53-64, 1998.

[19] J. Du, X. F. Wang, Q. M. Zhou et al., "Evodiamine induces apoptosis and inhibits metastasis in MDAMB-231 human breast cancer cells in vitro and in vivo," Oncology Reports, vol. 30, no. 2, pp. 685-694, 2013.

[20] M. Adams, A. Mahringer, O. Kunert, G. Fricker, T. Efferth, and R. Bauer, "Cytotoxicity and P-glycoprotein modulating effects of quinolones and indoloquinazolines from the Chinese herb Evodia rutaecarpa," Planta Medica, vol. 73, no. 15, pp. 1554-1557, 2007.

[21] N. S. Vyawahare, A. A. Hadambar, A. S. Chothe, R. R. Jalnapurkar, A. M. Bhandare, and M. K. Kathiravan, "Effect of novel synthetic evodiamine analogue on sexual behavior in male rats," Journal of Chemical Biology, vol. 5, no. 1, pp. 35-42, 2012.

[22] G. Dong, S. Wang, Z. Miao et al., "New tricks for an old natural product: discovery of highly potent evodiamine derivatives as novel antitumor agents by systemic structure-activity relationship analysis and biological evaluations," Journal of Medicinal Chemistry, vol. 55, no. 17, pp. 7593-7613, 2012.

[23] S. I. Kim, S. H. Lee, E. S. Lee, C. S. Lee, and Y. Jahng, "New topoisomerases inhibitors: synthesis of rutaecarpine derivatives and their inhibitory activity against topoisomerases," Archives of Pharmacal Research, vol. 35, no. 5, pp. 785-789, 2012.

[24] Z. Chen, G. Hu, D. Li et al., "Synthesis and vasodilator effects of rutaecarpine analogues which might be involved transient receptor potential vanilloid subfamily, member 1 (TRPV1)," Bioorganic and Medicinal Chemistry, vol. 17, no. 6, pp. 2351-2359, 2009.

[25] S.-J. Lin, H.-K. Lu, H.-W. Lee, Y.-C. Chen, C.-L. Li, and L.-F. Wang, "Nitric oxide inhibits androgen receptor-mediated collagen production in human gingival fibroblasts," Journal of Periodontal Research, vol. 47, no. 6, pp. 701-710, 2012.

[26] S.-H. Yu, Y.-T. Kao, J.-Y. Wu et al., "Inhibition of AMPK-associated autophagy enhances caffeic acid phenethyl ester-induced cell death in C6 glioma cells," Planta Medica, vol. 77, no. 9, pp. 907-914, 2011.

[27] F. M. Suk, W. J. Jou, R. J. Lin et al., "15, 16-dihydrotanshinone I-induced apoptosis in human colorectal cancer cells: involvement of ATF3," Anticancer Research, vol. 33, no. 8, pp. 3225-3231, 2013.

[28] C.-W. Lin, S.-C. Shen, C.-C. Chien, L.-Y. Yang, L.-T. Shia, and Y.C. Chen, "12-O-tetradecanoylphorbol-13-acetate-induced invasion/migration of glioblastoma cells through activating $\mathrm{PKC} \alpha /$ ERK/NF- $\kappa$ B-dependent MMP-9 expression," Journal of Cellular Physiology, vol. 225, no. 2, pp. 472-481, 2010.

[29] H. Henecka, H. Timmler, R. Lorenz, and W. Geiger, "Zur Kenntnis der Japp-Klingemann-Reaktion," Chemische Berichte, vol. 90, no. 6, pp. 1060-1069, 1957.

[30] K. Narayanan, L. Schindler, and J. M. Cook, "Carboxyl-mediated Pictet-Spengler reaction. Direct synthesis of 1,2,3,4-tetrahydro- $\beta$-carbolines from tryptamine-2-carboxylic acids," Journal of Organic Chemistry, vol. 56, no. 1, pp. 359-365, 1991.

[31] W.-F. Chiou, Y.-J. Sung, J.-F. Liao, A. Y.-C. Shum, and C.-F. Chen, "Inhibitory effect of dehydroevodiamine and evodiamine on nitric oxide production in cultured murine macrophages," Journal of Natural Products, vol. 60, no. 7, pp. 708-711, 1997.

[32] H. C. Yong, M. S. Eun, S. K. Yeong, F. C. Xing, J. L. Jung, and P. K. Hyun, "Anti-inflammatory principles from the fruits of Evodia rutaecarpa and their cellular action mechanisms," Archives of Pharmacal Research, vol. 29, no. 4, pp. 293-297, 2006. 
[33] Y. H. Hong, W. J. Lee, S. H. Lee et al., "Synthesis and biological properties of benzo-annulated rutaecarpines," Biological and Pharmaceutical Bulletin, vol. 33, no. 10, pp. 1704-1709, 2010.

[34] J.-R. Sheu, "Pharmacological effects of rutaecarpine, an alkaloid isolated from Evodia rutaecarpa," Cardiovascular Drug Reviews, vol. 17, no. 3, pp. 237-245, 1999.

[35] J. Yu, G.-S. Tan, P.-Y. Deng, K.-P. Xu, C.-P. Hu, and Y.-J. Li, "Involvement of CGRP in the inhibitory effect of rutaecarpine on vasoconstriction induced by anaphylaxis in guinea pig," Regulatory Peptides, vol. 125, no. 1-3, pp. 93-97, 2005.

[36] Y. J. Li, F. Zhang, Q. H. Gong, Q. Wu, L. M. Yu, and A. S. Sun, "Rutaecarpine inhibits angiotensin II-induced proliferation in rat vascular smooth muscle cells," Chinese Journal of Integrative Medicine, 2013.

[37] J. P. Thiery, H. Acloque, R. Y. J. Huang, and M. A. Nieto, "Epithelial-mesenchymal transitions in development and disease," Cell, vol. 139, no. 5, pp. 871-890, 2009.

[38] Y. Yoshimatsu and T. Watabe, "Roles of TGF-beta signals in endothelial-mesenchymal transition during cardiac fibrosis," International Journal of Inflammation, vol. 2011, Article ID 724080, 8 pages, 2011. 

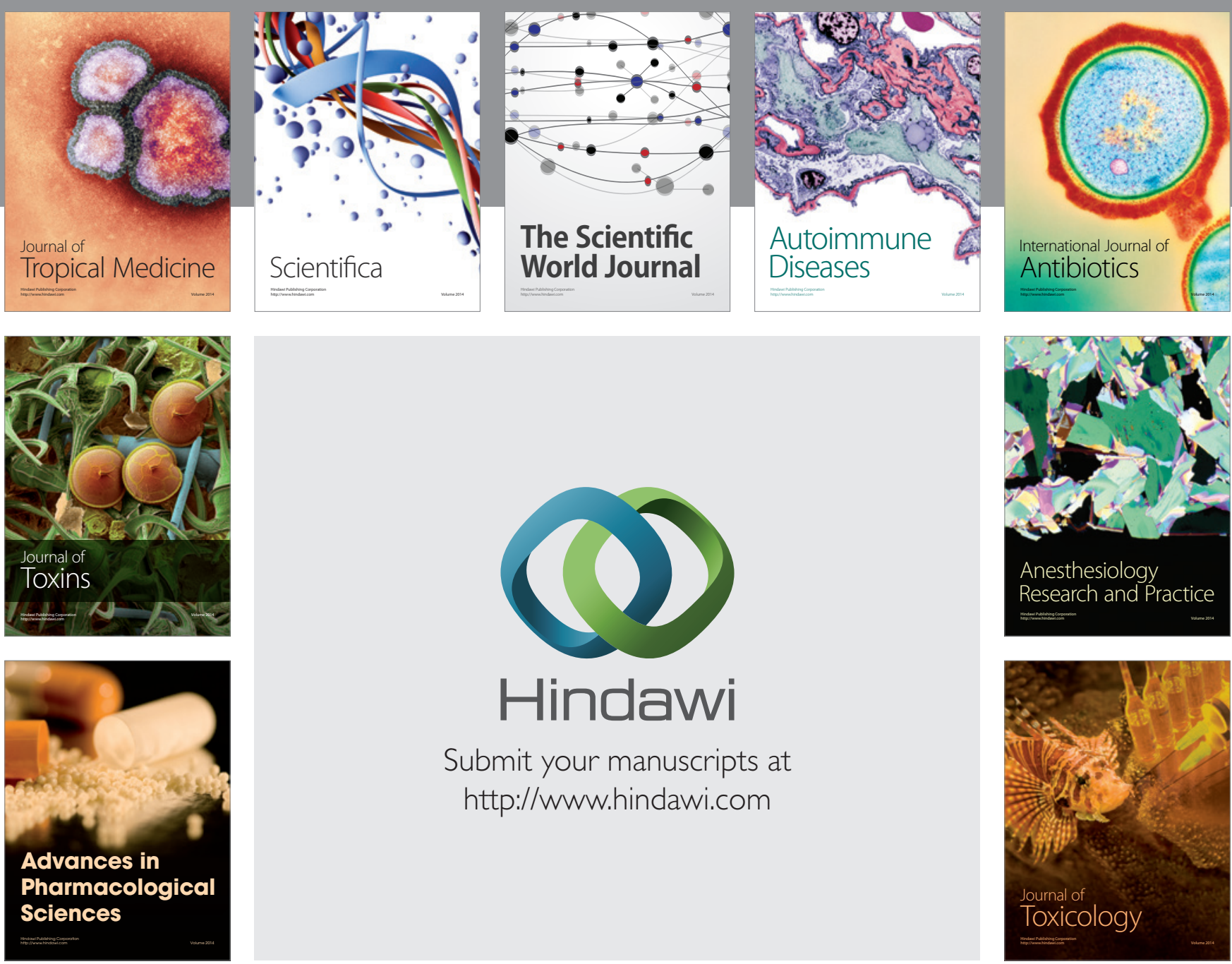

\section{Hindawi}

Submit your manuscripts at

http://www.hindawi.com
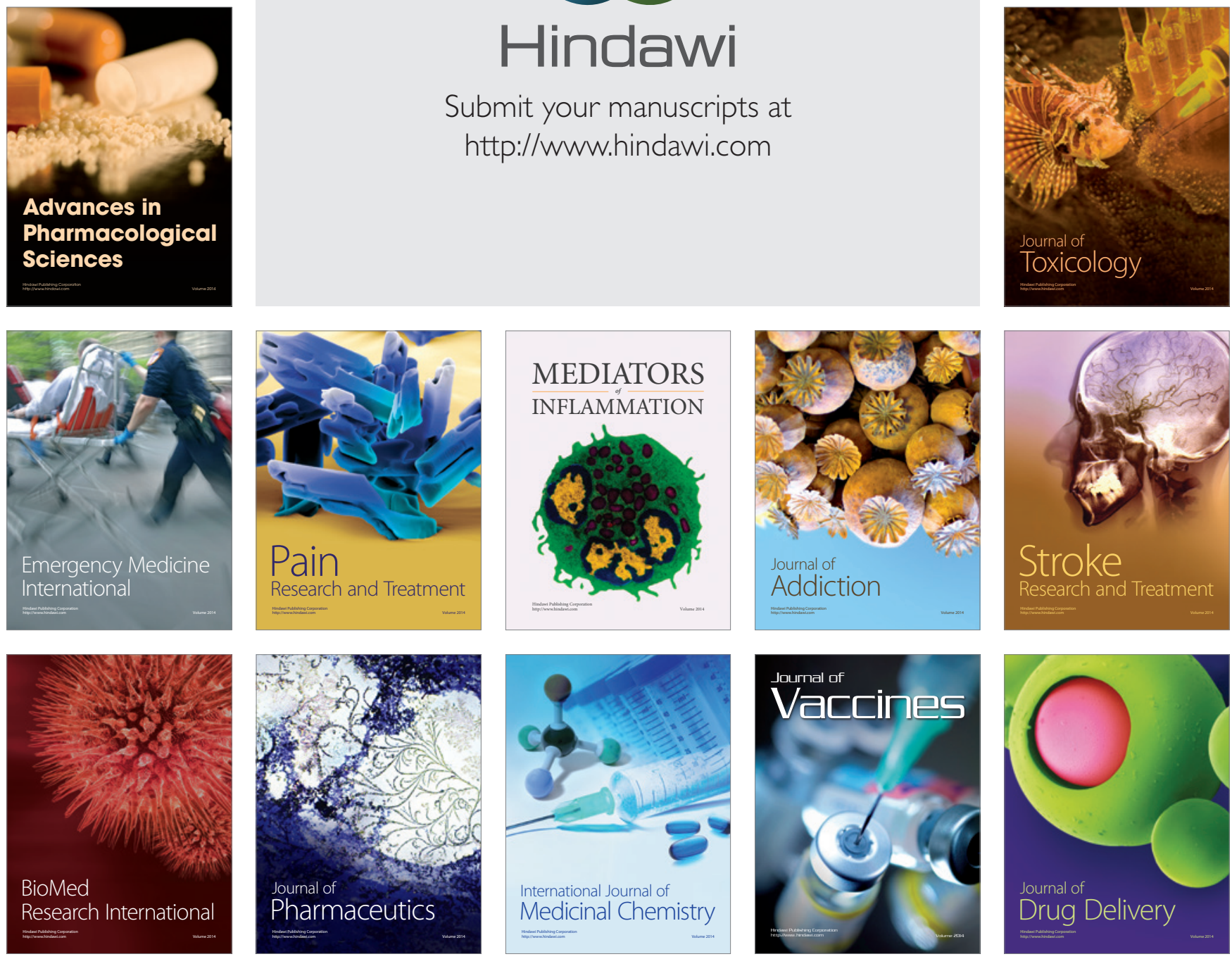